\title{
Influence of Hole Arrangement on the Section of Cavity Formed by Cutting Blast
}

\author{
Xianglong Li $\mathbb{D},{ }^{1,2}$ Qiang Li $\mathbb{D},{ }^{1}$ Jianguo Wang $\mathbb{D},{ }^{1,2}$ Zichen Wang, ${ }^{3}$ Hao Wang $\mathbb{D}^{4}$, \\ and Zihao Tao ${ }^{1}$ \\ ${ }^{1}$ Faculty of Land Resources Engineering, Kunming University of Science and Technology, Kunming, Yunnan, China \\ ${ }^{2}$ Yunnan Key Laboratory of Sino-German Blue Mining and Utilization of Special Underground Space, Kunming University of \\ Science and Technology, Kunming, Yunnan, China \\ ${ }^{3}$ Xi'an Research Institute of China Coal Technology Group Co., Ltd., Xi'an, Shanxi, China \\ ${ }^{4}$ State Key Laboratory of Reservoir Geology and Development Engineering, Southwest Petroleum University, Chengdu, \\ Sichuan, China \\ Correspondence should be addressed to Jianguo Wang; wangjg0831@163.com
}

Received 11 August 2021; Revised 10 October 2021; Accepted 27 October 2021; Published 11 November 2021

Academic Editor: Haojie Lian

Copyright (C) 2021 Xianglong Li et al. This is an open access article distributed under the Creative Commons Attribution License, which permits unrestricted use, distribution, and reproduction in any medium, provided the original work is properly cited.

In order to optimize the arrangement of cutting holes in tunnel blast in Dahongshan Copper Mine, theoretical analysis and numerical simulation were combined to preliminarily determine the diameter of the hollow hole and the distance between the charge hole and the hollow hole during cut blast, which was verified through the field blast test. The research results show that with the increase of the hole diameter, the peak compressive stress of rock surrounding the empty hole gradually decreases, and the peak tensile stress gradually increases, which is consistent with the calculation results; when the hole diameter is $10 \mathrm{~cm}$, the two first blast holes are arranged horizontally and $30 \mathrm{~cm}$ from the empty hole, two second blast holes are arranged vertically and $40 \mathrm{~cm}$ away from the empty hole, and the four third blast holes are arranged at a horizontal distance of $45 \mathrm{~cm}$ and a vertical distance of $45 \mathrm{~cm}$ from the empty hole; the contour area in numerical simulation is the maximum. The difference in contour area, contour width, and contour and contour height between the measured value and the simulation result is $5.3 \%, 3.3 \%$, and $3.4 \%$, respectively, indicating that the combination of theoretical calculation and numerical simulation is suitable for prediction of cavity section after blast in tunnel excavation.

\section{Introduction}

Cutting blast is a widely used technology for tunnel excavation, which creates a new free surface and more favorable blast conditions for other blast holes. Compared to other alternatives, for example, pulse fracturing [1] and hydraulic fracturing [2], cutting blast is more suitable for hard rocks and has low cost. During tunneling, there is only one free surface, and the surrounding rocks show great blast containment, inducing challenging blast conditions. By arranging large diameter holes in the cutting area, the stress concentration effect of the hollow holes, the free surface effect, and the unloading pressure effect can be used to improve the blast effect [3]. During the cutting blast, the hollow hole not only provides the initial compensation space for the rock swelling of the groove cavity but also changes the stress distribution in the rock near the hollow hole and the blast effect of the adjacent slot hole. This phenomenon is called the empty hole effect of cutting blast. Because the hole effect plays an important role in promoting rock breaking, throwing, and cavity formation, it has been focused on by many scholars [4].

Mohanty [5] first proposed to set up empty holes between the blast holes to control the propagation direction of blast crack. Cho et al. [6] used a combination of numerical simulation and experiment to study the directional fracture effect of empty holes. Lai [7] established the calculation model of cutting blast effect on the basis of theoretical analysis. Under certain conditions, the quantitative relationship between the cutting efficiency and the hole diameter, the depth of the cut hole, and the hole distance between the 
cut hole and the empty hole is obtained. Wu et al. [8] used ANSYS to simulate the distribution and variation trend of dynamic stress around blasting holes under different ground stress conditions. Tian et al. [9] based on the action mechanism of empty hole directional blasting, the influence of charge hole spacing on crack propagation is studied, deduced the calculation formula of charge hole spacing, and carried out numerical simulate of tunnel blasting excavation process. Li et al. [10] use ANSYS/LS-DYNA to simulate the process of rock fragmentation of double blast holes blasting with one empty hole at the center position. The rock fragmentation effect by blasting, the propagation of cracks between adjacent blast holes, and the pressure state of the element near the empty hole are analyzed. Zheng [11] used ANSYS simulation software to realize the visualization of the cavity formation and pressure propagation of cut blast and concluded that the blast effect is related to the distance between the charging hole to the empty hole. Zong et al. [12] used the cavity formation mechanism to explain the principle of adding holes in the deep hole vertical cutting. Zhu et al. [13] used numerical simulation methods to conduct comparative analysis of the single-hole cutting schemes under different diameter holes and found that the hole has the effect of reflecting stress waves and accumulating explosion energy, and its effect becomes more obvious as the increase of the hole diameter. Yue et al. [14] used the caustics test system to study the directional fracture failure under different hole shapes, and it was concluded that the diamond-shaped hole has the best effect on the directional propagation of the crack. By establishing the basic mechanical model of the straight hole cutting, Zhang Qi [15] quantitatively analyzed the influence of hole diameter on cutting effect of straight hole by numerical calculation; Li et al. [16] used explicit dynamic analysis software to simulate the crack penetration between the cut hole and empty holes with different diameters. The results show that as the hole diameter increased, the rock breaking extended failure area and compression failure area became more obvious; through numerical calculation, Wang et al. [17] found that the empty hole has the advantages of increasing the peak value of the stress wave and prolonging the action time. The stress wave in the rock mass around the empty hole was 2.2 times that of the traditional straight-hole cutting, which made the rock fragmentation more uniform and reduced the block rate. At the same time, the phenomenon of stress superposition and reflection of tensile explosion stress wave at the empty hole and the guiding role of the empty hole are intuitively displayed.

However, in terms of the cutting blast under the hollow hole arrangement, there is little research about the arrangement of the cutting holes. In this paper, the distance range was obtained through theoretical calculation, and the calculation result was simulated with LS-DYNA simulation software. Besides, different distances between the cutting holes and the hollow holes of the segmented detonation were simulated. Thus, the rock crushing range was determined to obtain the arrangement of the cutting hole and the distance between the empty holes until the hole network parameters of the cut holes are finally determined and used as a basis for field tests. The test results show that the combination of theoretical calculations and numerical simulations can be used to predict the contour section after the blast of the cutting hole in tunnel excavation.

\section{Theoretical Calculation of Vertical Cutting}

2.1. Calculation of the Radius of the Rock Crushing Zone and the Fracture Zone under the Coupled Charge Condition. According to the roadway excavation requirements of Dahongshan Copper Mine of Yuxi Mining, the middle section of $330 \mathrm{~m} \sim 400 \mathrm{~m}$ was taken as a research subject, which is located in the third rock section of the Lower Proterozoic Manganghe Formation. This section is mainly composed of marble, and the overall rock quality is medium. The integrity of the rock mass is medium, and the surrounding rock of the chamber is stable during mining or roadway excavation. The geological type is the layered and quasilayered deposits dominated by hard and semihard rock groups and medium engineering geological conditions. There are locally wave-shaped undulating monoclinal structures and four groups of faults. The specific mechanical parameters $[18,19]$ are shown in Table 1:

The explosive used in blast is No. 1 rock emulsion explosive, and the parameters are shown in Table 2 below.

The radius of the rock crushing zone and the fracture zone of the coupled charge conditions are, respectively [20],

$$
\left\{\begin{array}{l}
R_{c}=\left(\frac{\rho_{0} D_{0}^{2} A B}{4 \sqrt{2} \sigma_{c d}}\right)^{1 / \alpha} r \\
A=\frac{2 \rho_{m} C_{p}}{\rho_{m} C_{p}+\rho_{0} D_{0}}, \\
B=\left[(1+\lambda)^{2}+(1+\lambda)-2 \mu_{d}\left(1-\mu_{d}\right)(1-\lambda)^{2}\right]^{1 / 2} \\
R_{t}=\left(\frac{\sigma_{c d}}{\sigma_{t d}}\right)^{1 / \beta}\left(\frac{\rho_{0} D_{0}^{2} A B}{4 \sqrt{2} \sigma_{c d}}\right)^{1 / \alpha} r
\end{array}\right.
$$

where $R_{\mathrm{c}}$ is the radius of the crushing zone $(\mathrm{m}), \rho_{\mathrm{e}}$ is the rock density $\left(\mathrm{kg} / \mathrm{m}^{3}\right), C_{p}$ is the velocity of the longitudinal wave in the rock, $\rho_{0}$ is the explosive density, $D_{0}$ is the detonation velocity of explosive, $\sigma_{\mathrm{cd}}$ is the uniaxial dynamic compressive strength of the rock $(\mathrm{MPa}), \sigma_{\mathrm{cd}}=\sigma_{\mathrm{c}} \dot{\varepsilon}^{1 / 3}, \sigma_{\mathrm{c}}$ is the uniaxial static compressive strength of rock, and $\dot{\varepsilon}$ is the strain loading rate $\left(\mathrm{s}^{-1}\right)$, which is between $10^{0}$ and $105 \mathrm{~s}^{-1}$ in engineering blast. In the compression ring, the loading rate is higher, which can be taken as $\dot{\varepsilon}=10^{2} \sim 104$ $\mathrm{s}^{-1}$; outside the compression ring, the loading rate is further reduced and can be taken as $\dot{\varepsilon}=10^{0} \sim 103 \mathrm{~s}^{-1} ; \lambda$ is the lateral stress coefficient, $\lambda=\mu_{\mathrm{d}} /\left(1-\mu_{\mathrm{d}}\right) ; R_{t}$ is the radius of the crack zone $(\mathrm{m}) ; \alpha$ is the attenuation index of shock wave propagation; $\mu_{\mathrm{d}}$ is the dynamic Poisson's ratio of the rock,; $r$ is the blast hole radius; $\mu$ is the static Poisson's ratio of the rock; $\sigma_{\mathrm{td}}$ is the dynamic tensile strength of the rock, due to the dynamic tensile strength of the rock changes little with loading strain rate. Within the range of strain loading rate of rock engineering blast, $\sigma_{t d}=\sigma_{t} ; \sigma_{t}$ is the uniaxial static 
TABle 1: Statistics of physical and mechanical parameters of marble in Dahongshan Copper Mine.

\begin{tabular}{|c|c|c|c|c|c|c|c|c|}
\hline \multirow[b]{2}{*}{$\begin{array}{l}\text { Rock } \\
\text { type }\end{array}$} & \multirow[b]{2}{*}{$\begin{array}{l}\text { Compressive } \\
\text { strength/MPa }\end{array}$} & \multirow{2}{*}{$\begin{array}{c}\text { Tensile } \\
\text { strength/MPa }\end{array}$} & \multicolumn{2}{|c|}{ Shear strength } & \multirow[b]{2}{*}{$\begin{array}{c}\text { Elastic } \\
\text { modulus/GPa }\end{array}$} & \multirow[b]{2}{*}{$\begin{array}{l}\text { Poisson's } \\
\text { ratio }\end{array}$} & \multirow{2}{*}{$\begin{array}{l}\text { Density/ } \\
\mathrm{kg} \cdot \mathrm{m}^{-3}\end{array}$} & \multirow{2}{*}{$\begin{array}{l}\text { Longitudinal wave } \\
\text { speed } / \mathrm{m} \cdot \mathrm{s}^{-1}\end{array}$} \\
\hline & & & $\begin{array}{c}\text { Internal } \\
\text { cohesion/MPa }\end{array}$ & $\begin{array}{c}\text { Internal } \\
\text { friction angle } /^{\circ}\end{array}$ & & & & \\
\hline Marble & 69.31 & 8.34 & 3.662 & 47.35 & 73.83 & 0.268 & 2908 & 3341 \\
\hline
\end{tabular}

TABLE 2: Basic parameters of explosives.

\begin{tabular}{lcccc}
\hline $\begin{array}{l}\text { Cartridge } \\
\text { density/ } \\
\mathrm{g} \cdot \mathrm{cm}^{-3}\end{array}$ & $\begin{array}{c}\text { Detonation } \\
\text { transmission } \\
\text { distance } / \mathrm{cm}\end{array}$ & $\begin{array}{c}\text { Detonation } \\
\text { velocity/ } \\
\mathrm{m} \cdot \mathrm{s}^{-1}\end{array}$ & $\begin{array}{c}\text { Function } \\
\text { force } / \mathrm{ml}\end{array}$ & $\begin{array}{c}\text { Ferocity/ } \\
\mathrm{mm}\end{array}$ \\
\hline $0.95 \sim 1.30$ & $\geq 4$ & $\geq 4500$ & $\geq 320$ & $\geq 16.0$ \\
\hline
\end{tabular}

tensile strength of the rock, and $\beta$ is the stress attenuation index, which is rewritten as $\beta$ to distinguish from the crushing zone, $\beta=2-\mu_{\mathrm{d}} /\left(1-\mu_{\mathrm{d}}\right)$.

Thus, the radius of the crushing zone $R_{c}$ and the radius of the crack zone $R_{t}$ are determined to be $5.73 \mathrm{~cm}$ and $28.50 \mathrm{~cm}$, respectively.

2.2. Diameter of Empty Hole. The surface of the empty hole is equivalent to the free surface, which has a directional effect on the broken rock. When the diameter of the empty hole is equal to or smaller than the diameter of the charge hole, the wave surface formed by the reflected stress wave is more convex than the incident wave surface, the degree of divergence is higher, so that the explosion energy is quickly attenuated, and the free surface of the empty hole has less effect. In order to improve the free effect of the empty holes and make full use of explosive energy to break the rocks, during the linear cutting, the diameter of the empty hole should be increased as much as possible or setting multiple small diameter holes. As the same time, the empty hole is also arranged to the location where stress is concentrated, and cracks are most likely to occur, because the empty hole provides expansion space for broken rocks. Cutting blast not only breaks the rock in the cavity but also pushes the broken rock out of the cavity so as to provide a new free surface for the rear blast hole [21]. Considering the construction efficiency, a single large diameter hole was selected and arranged in the middle of the cutting area.

According to the actual engineering situation, during rock drilling, the pore-forming velocity often decreases with the increase of the diameter of the empty hole. But in a certain range, the pore-forming velocity of blast holes does not need to decrease significantly with the increase of the hole diameter. The charge hole diameter in Dahongshan Copper Mine is $50 \mathrm{~mm}$. When the diameter of the empty hole is larger than the aperture of the slot and the formula (2) is satisfied, not only the rock between the hole and the slot can be broken but also a crushing funnel can be formed [22]:

$$
\frac{D}{d} \geq(1+\sin \delta / 2) /(1-\sin \delta / 2)=1.7
$$

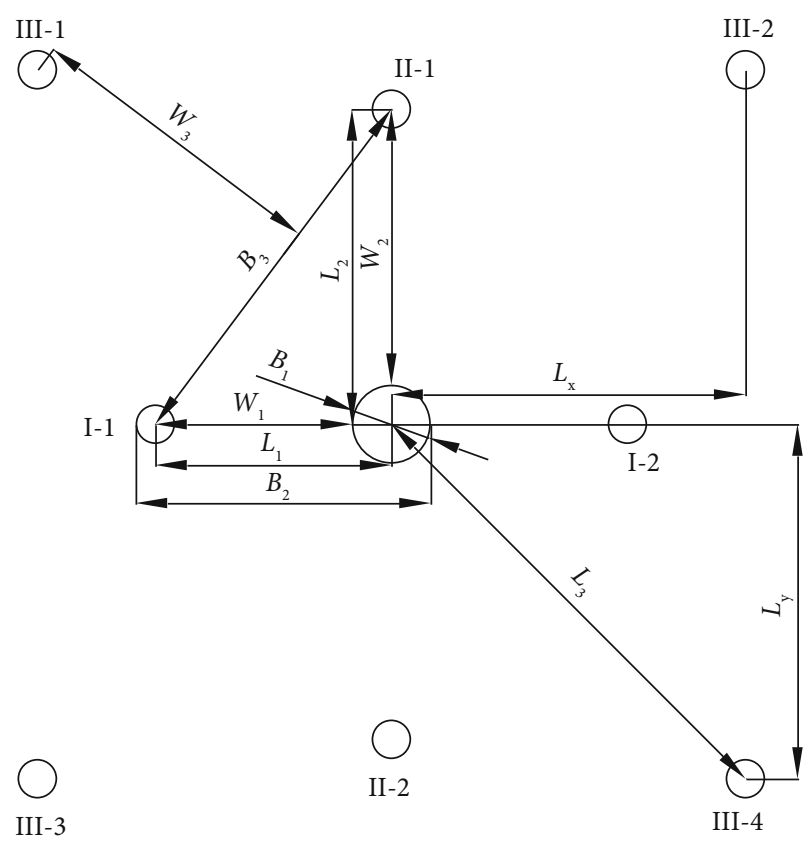

FIgURE 1: Schematic diagram of the layout position of the vertical cut of the empty hole.

where $D$ is the diameter of the empty hole, $d$ is the diameter of the charge hole, and $\delta$ is the rock blast fracture angle. When vertical cutting is used, $\delta>30^{\circ}$ is required.

Through theoretical analysis and calculation, the diameter of the hollow hole should be greater than the diameter of the charge hole, and their ratio needs to be greater than 1.7 , that is, $D \geq 8.5 \mathrm{~cm}$. In order to form sufficient compensation space, a large diameter empty hole must be selected while cutting free surface and parallel to the blast hole.

2.3. Determination of Hole Distance. The layout of the blasting hole is shown in Figure 1. In the middle, there is an empty hole; the first blast hole is I-1 and I-2; the second blast hole is II -1 and II -2; the third blast hole is III-1, III-2, III-3, and III-4.

2.3.1. The Distance between the First Blast Hole and the Empty Hole. The distance between the first blast hole and the empty hole is mainly determined by the explosion energy, the volume of the blast hole, the explosion action index, and the blast hole deflection [23].

(1) The Influence of the Crushing Radius. Because the rock mass blasted by the first blast hole should be located in the fissure zone of the first blast hole, the center distance $L_{1}$ 
between the first blast hole and the empty hole should be less than the radius of the fissure zone, that is:

$$
L_{1} \leq R_{t}+D / 2
$$

where $L_{1}$ is the distance between the first blast hole and the hollow hole, and the diameter of the hollow hole is $10 \mathrm{~cm}$ according to the simulation result and $L_{1} \leq 33.50 \mathrm{~cm}$.

(2) The Influence of the Expansion Margin. The distance between the first blast hole and the empty hole should be greater than the radius of the crushing ring and smaller than the radius of the crack ring. When the hole spacing is less than the radius of the crushing, the groove may be "squeezed" due to excessive rock crushing or adjacent damage, which leads to the occurrence of rejection. When the blast hole spacing is greater than the radius of the fissure zone, it may cause insufficient rock fragmentation and fail to form a complete blast cavity. The volume of the empty hole should be close to the volume increment induced by the swelling of the rock under the impact of the first blast hole; therefore, this distance can be obtained:

$$
L_{1} \leq \frac{\pi}{2(R+r)}\left[\frac{2\left(h r^{2}+R^{2}\right)}{K-1}+R^{2}+r^{2}\right]
$$

where $R$ is the radius of the hole, $r$ is the radius of the charge hole, $h$ is the charge coefficient, and $K$ is the breaking expansion coefficient of the rock, which was taken as $K=1.5$ in this paper. The diameter of the charge hole is $5 \mathrm{~cm}$, and the solution is $L_{1} \leq 31.68 \mathrm{~cm}$.

(3) The Influence of the Type of Crushing. When the crushed rock is completely thrown out, the distance between the first blast hole and the center of the hollow hole is

$$
L_{1}=\frac{2 \pi}{\varepsilon}\left(\frac{R^{2}+r^{2}}{R+r}\right)+R+r
$$

where $\varepsilon$ is the coefficient relating to the rock type, lithology, and structure, and it is 2 in this research; after calculation, $L_{1}=21.28 \mathrm{~cm}$.

(4) The Influence of the Blast Hole Deflection. In order to prevent the penetration between the blast holes, formula (6) needs to be satisfied:

$$
L_{1}>\frac{D+d}{2}+2 H \sin a
$$

where $H$ is the depth of the blast hole, and $a$ is the deflection angle of the blast hole.

In Dahongshan Copper Mine, the rock drilling rig is a Kaishan brand KJ311 full hydraulic tunneling drill ring. The blast hole deflection angle can be controlled within $1^{\circ}$; so, it was calculated that $L_{1}>18.67 \mathrm{~cm}$.
TABLE 3: Explosive materials and state equation parameters.

\begin{tabular}{lcccccc}
\hline$\rho /\left(\mathrm{g} / \mathrm{cm}^{3}\right)$ & $D_{0} /(\mathrm{m} / \mathrm{s})$ & $A / \mathrm{GPa}$ & $B / \mathrm{GPa}$ & $R_{1}$ & $R_{2}$ & $\omega$ \\
\hline 1.3 & 4500 & 214.4 & 0.182 & 4.2 & 0.9 & 0.15 \\
\hline
\end{tabular}

After comprehensively analyzing the influencing factors above, the distance range between the first blast hole and the empty hole is determined to be in the range $18.67 \mathrm{~cm}$ $<L_{1}<31.68 \mathrm{~cm}$.

2.3.2. Distance from Blast Hole to the Empty Hole. The optimal resistance line and the free surface width of the charge can be determined according to the following empirical formula (7) [24]:

$$
W=\left(d \frac{1.95 e}{\sqrt{\rho_{e}}}+2.3-0.0027 B\right)(0.1 B+2.16)
$$

where $e$ is the correction coefficient of explosion force, which is 0.89 in this project, $B$ is the width of the free surface, and $W$ is the optimal resistance line of the segmented blast hole.

The hole layout diagram is shown in Figure 1. The distance between the first shot hole and the empty hole is $L_{1}$ $=18.67 \mathrm{~cm} \sim 31.68 \mathrm{~cm}$, the free surface width is $B_{2}=L_{1}+$ $D /{ }_{2}+d /{ }_{2}, B_{2}=26.17 \mathrm{~cm} \sim 39.18 \mathrm{~cm}$, the optimal resistance line of the second shot hole is $W_{2}$ by formula (7), $W_{2}=$ $31.92 \mathrm{~cm} \sim 38.48 \mathrm{~cm}$, and then the distance between the second shot hole and the empty hole is $L_{2}=W_{2}+D / 2, L_{2}=$ $36.92 \mathrm{~cm} \sim 43.48 \mathrm{~cm}$. The free surface width of the third shot hole is $B_{3}=\sqrt{L_{1}^{2}+L_{2}^{2}}+D / 2+\mathrm{d} / 2, B_{3}=48.87 \mathrm{~cm} \sim 61.29 \mathrm{~cm}$. The optimal resistance line of the third shot hole is $W_{3}$ obtained by formula (7), $W_{3}=42.77 \mathrm{~cm} \sim 47.53 \mathrm{~cm}$, and then the distance between the third shot hole and the empty hole is $L_{3}=W_{3}+L_{1} \cdot L_{2} / \sqrt{L_{1}^{2}+L_{2}^{2}}, \quad L_{3}=59.43 \mathrm{~cm} \sim 73.13$ $\mathrm{cm}$. The optimal resistance line of each charge hole is related to the width of the free surface, namely, the distance between the blast hole and the empty hole.

\section{Numerical Simulation of Cut Hole Layout Parameters}

3.1. Geometric Model. The ANSYS/LSDYNA was used to establish a two-dimensional finite element model with the size of $400 \mathrm{~cm} \times 400 \mathrm{~cm}$, in which the edge is defined as a nonreflective boundary, the blast hole diameter is $5 \mathrm{~cm}$, the charge method is coupled charge, the charge diameter is $5 \mathrm{~cm}$, and the holes with large diameter are located in the center of the model. The blast hole layout is shown in Figure 1.

Experimental scheme is as follows:

(1) After calculating the diameter of the hole, referring to the commonly used drill bits in the mine, the horizontal distance between the charging hole and the hole was set to $20 \mathrm{~cm}$. The diameter of large holes used in China is $7.5 \mathrm{~cm} \sim 10 \mathrm{~cm} \mathrm{[17];} \mathrm{so,} D$ was selected as $7 \mathrm{~cm}, 7.5 \mathrm{~cm}, 8 \mathrm{~cm}, 9 \mathrm{~cm}, 10 \mathrm{~cm}$, and 
TABLE 4: Marble HJC constitutive model parameters.

\begin{tabular}{lccccccccc}
\hline$\rho_{0} / \mathrm{kg} \cdot \mathrm{m}^{-3}$ & $f_{c} / \mathrm{MPa}$ & $A$ & $B$ & $C$ & $S_{\max }$ & $G$ & $T$ & $D_{1}$ & $D_{2}$ \\
\hline 2908 & 69.31 & 0.52 & 1.17 & 0.0163 & 4 & 22.27 & 8.34 & 0.036 & 1 \\
$P_{\text {crush }} / \mathrm{MPa}$ & $\mu_{\text {crush }}$ & $P_{\text {lock }} / \mathrm{GPa}$ & $\mu_{\text {plock }}$ & $K_{1}$ & $K_{2}$ & $K_{3}$ & $E F_{\text {min }}$ & $N$ & $F S$ \\
23.65 & 0.00076 & 0.159 & 0.012 & 13 & 23 & 60 & 0.01 & 0.79 & 0.085 \\
\hline
\end{tabular}

TABle 5: Peak tensile stress of the hole wall with different hole diameters.

\begin{tabular}{lcccccc}
\hline Empty hole diameter/cm & 7 & 7.5 & 8 & 9 & 10 & 12.5 \\
\hline Simulated peak tensile stress/MPa & 176 & 189 & 191 & 199 & 219 & 235 \\
Calculate peak tensile stress/MPa & 219 & 227 & 234 & 247 & 263 \\
\hline
\end{tabular}

$12.5 \mathrm{~cm}$, respectively, and the two charge holes I-1 and $\mathrm{I}-2$ detonate at the same time

(2) After the scheme (1), the hole diameter was determined to be $10 \mathrm{~cm}$, the blast hole and the empty hole were arranged horizontally, the distance between the first blast hole and the empty hole $L_{1}$ was set as $20 \mathrm{~cm}, 25 \mathrm{~cm}$, and $30 \mathrm{~cm}$, respectively, and two blast holes I-1 and I-2 were set to detonate at the same time

(3) After determining the distance between the first blast hole and the empty hole, through the empirical formula, different hole spacings for the second blast hole were, respectively, set as $35 \mathrm{~cm}, 40 \mathrm{~cm}$, and $45 \mathrm{~cm}$ for simulation, and the second blast hole was arranged along the longitudinal direction. The two first blast holes I- 1 and I-2 were detonated at the same time. After the failure of the rock-free unit, the two second blast holes II-1 and II-2 were detonated again

(4) While calculating the distance $59.43 \mathrm{~cm} \leq L_{3} \leq$ $73.13 \mathrm{~cm}$ between the third shot hole and the empty hole through the empirical formula, the blast holes were arranged symmetrically around the empty hole, and their horizontal and vertical distances were $42.02 \mathrm{~cm} \leq L_{x} \leq 51.71 \mathrm{~cm}$ and $42.02 \mathrm{~cm} \leq L_{y} \leq 51.71$ $\mathrm{cm}$, respectively. In order to verify the accuracy of this parameter, set the horizontal distances $L_{x}$ and vertical distances $L_{y}$ spacing of the third blast hole was set to be $40 \mathrm{~cm}, 45 \mathrm{~cm}, 50 \mathrm{~cm}$, and four third blast holes III-1, III-2, III-3, and III-4 detonated simultaneously after the first and second blast holes that were detonated, and the rock-free unit continued to fail

3.2. Material Model and Parameters. The explosive used in the field is the No. 1 rock emulsion explosive [16], the model *MAT_HIGH_EXPLOSIVE_BURN is selected, and the state equation is defined by the keyword *EOS_JWL, which is used to describe the volume, pressure, and energy characteristics of the explosion. The equation parameters of explosive material and state used in this article are shown in Table 3. Many constitutive models have been proposed to describe the effect of brittle materials under blast impact. According to the existing data of Dahongshan Copper Mine, various parameters of the marble material model can be obtained, as shown in Table 4 [25]. Using the *MAT_ADD_ EROSION to define the tensile strength of the rock, when the effective stress of the element reaches the tensile strength, it will automatically disappear; thus, the dynamically displaying the broken process of the cut hole and the hollow hole can be realized [26, 27].

The rock fragmentation area is judged based on the failure of the rock element or the unfailed rock element that is separated from the surrounding rock mass, and the rock in the area is considered to be completely broken. If there is a slender area with a width of 1 unit, it is judged to be a crack, and the rock in this area is not included in the statistics.

3.3. Selection of Empty Hole Diameter. After the explosion of the charge hole, the shock wave decays into a stress wave propagating in the rock, and when it reaches the wall of the hole, it will be reflected. The stress of the rock near the hole is larger than that of the condition without a hole. Because this is a hollow hole, the stress is concentrated, and the maximum tensile stress is generated at the connection line between the blast hole and the hollow hole. When this stress is greater than the dynamic tensile strength of the rock, radial cracks will appear at the hollow hole; as the structure is continuously charged, the initial maximum tensile stress around the blast hole can be expressed as follows [28-38]:

$$
\begin{aligned}
P & =T C_{p}=\frac{2 \rho_{0} C_{p}}{\rho_{0} C_{p}+\rho_{0} D} \times \frac{\rho_{e} D^{2}}{\gamma+1}, \\
\sigma_{\theta \theta \max } & =(3 \lambda+1) P\left(\frac{r_{1}}{L_{1}-r_{2}}\right)^{\alpha},
\end{aligned}
$$

where $\sigma_{\theta \theta \max }$ is the maximum peak value of tensile stress at the hole wall after blast $(\mathrm{MPa}), r_{1}$ is the radius of the blast hole $(\mathrm{m})$, and $r_{2}$ is the radius of the hole $(\mathrm{m})$.

Under conditions of different hole diameters, the maximum tensile stress at the hole wall can be calculated, as shown in Table 5. According to Scheme 1, while simulating different hole diameters, the pressure history curves are shown in Figure 2, and the maximum tensile stress at the 


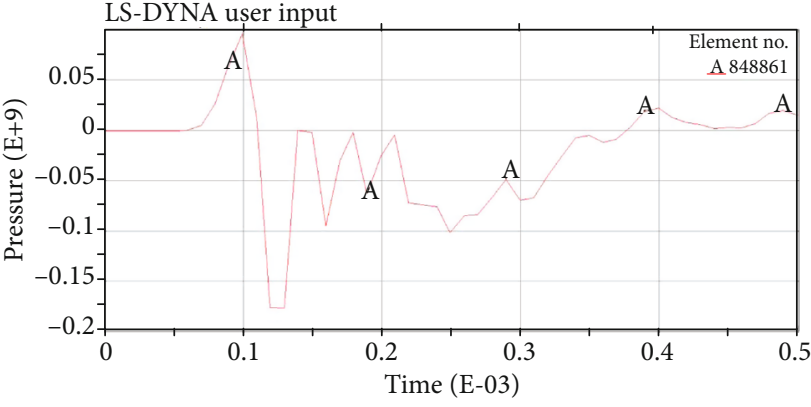

$\min =\mathrm{A}(0.00013,-1.76 \mathrm{e}+08)$

$\max =\mathrm{A}(9.96 \mathrm{e}-05,9.67 \mathrm{e}+07)$

(a) $D=7 \mathrm{~cm}$

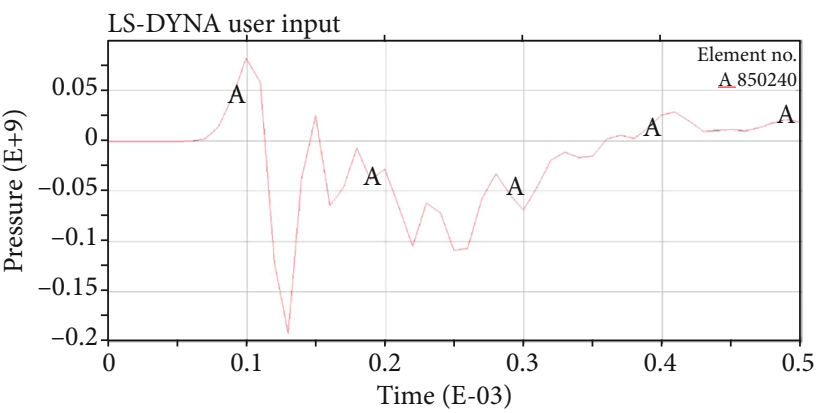

$\min =\mathrm{A}(0.00013,-1.91 \mathrm{e}+08)$

$\max =\mathrm{A}(9.96 \mathrm{e}-05,8.22 \mathrm{e}+07)$

(c) $D=8 \mathrm{~cm}$

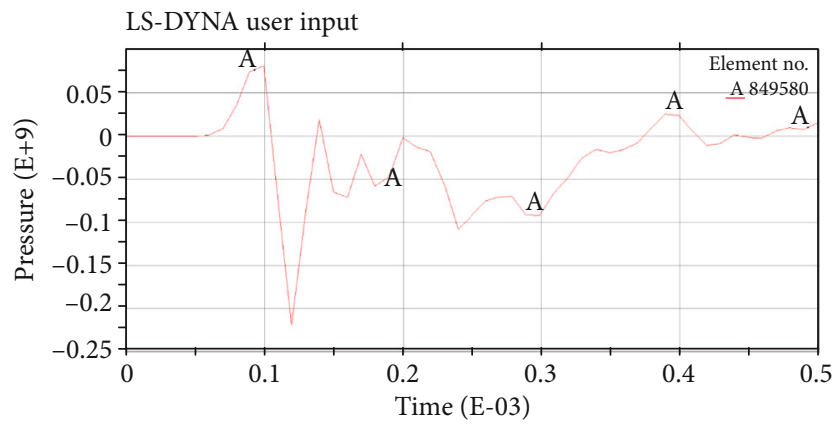

$\min =\mathrm{A}(0.000119,-2.19 \mathrm{e}+08)$

$\max =\mathrm{A}(9.96 \mathrm{e}-05,8.14 \mathrm{e}+07)$

(e) $D=10 \mathrm{~cm}$

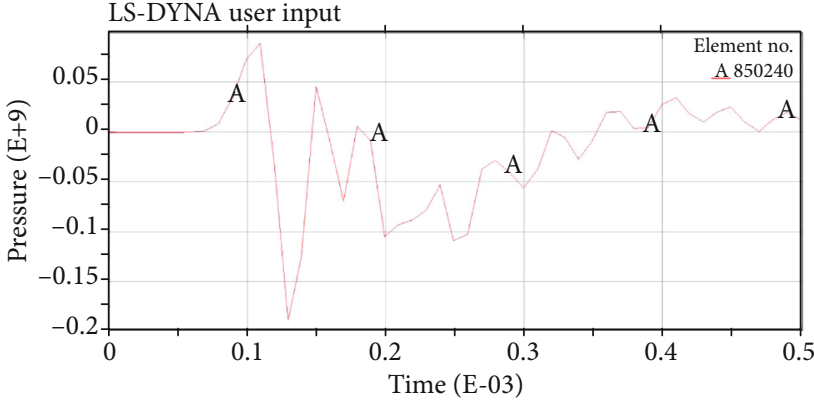

$\min =\mathrm{A}(0.00013,-1.89 \mathrm{e}+08)$

$\max =\mathrm{A}(0.00011,8.98 \mathrm{e}+07)$

(b) $D=7.5 \mathrm{~cm}$

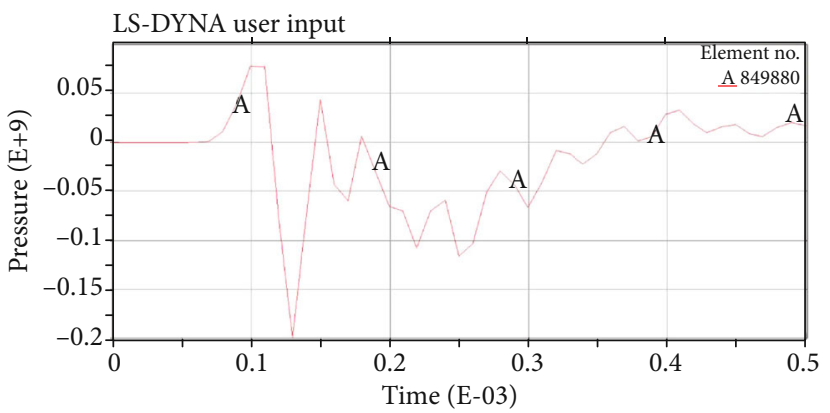

$\min =\mathrm{A}(0.00013,-1.99 \mathrm{e}+08)$

$\max =\mathrm{A}(9.96 \mathrm{e}-05,7.83 \mathrm{e}+07)$

(d) $D=9 \mathrm{~cm}$

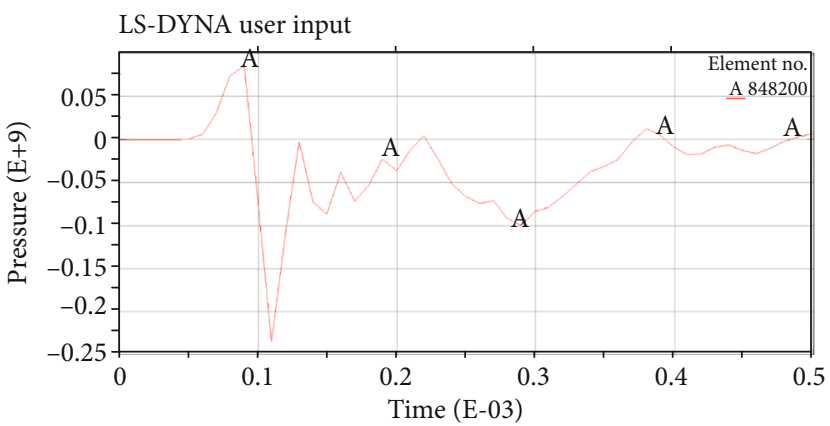

$\min =\mathrm{A}(0.00011,-2.35 \mathrm{e}+08)$

$\max =\mathrm{A}(8.99 \mathrm{e}-05,8.57 \mathrm{e}+07)$

(f) $D=12.5 \mathrm{~cm}$

Figure 2: Pressure time history curve of hole wall under different hole diameters.

hole wall can be obtained. The calculation results and simulation results are plotted in Figure 3, and it can be seen that the calculation and simulation results are basically consistent with each other; they both increase with the increase of the hole diameter.

It can be seen from Figure 2 that with the hole diameter increases from $7 \mathrm{~cm}$ to $12.5 \mathrm{~cm}$, the distance between the hole wall and the first blast hole gradually decreases; so, the time of reaching the peak compressive stress of the rock surrounding the hole wall decreases from $99.6 \mu$ s to $89.9 \mu \mathrm{s}$, and the peak compressive stress is reduced from $96.7 \mathrm{MPa}$ to $85.7 \mathrm{MPa}$, indicating that when the shock wave is far away from the center of the blast hole, the shock wave continues to attenuate, and the stress value continues to drop. At the same time, the time of reaching the peak tensile stress decreases from $130 \mu$ s to $110 \mu \mathrm{s}$, and the peak tensile stress increases from $176 \mathrm{MPa}$ to $235 \mathrm{MPa}$, indicating when the compression wave propagates to the cavity, it will be reflected to form a tensile wave and has the same effect as the initial stress wave propagated to the free surface. It can also be known that the tensile stress of the rock around the wall of the cavity increases with the increase of the diameter of the cavity, and the larger the diameter of the cavity, the easier it is for the surrounding rock to be damaged by tension, which is helpful to the formation of the cavity. Considering the existing rock drilling equipment and rock drilling cost of Dahongshan Copper Mine, the diameter of the hole is selected as $10 \mathrm{~cm}$. 


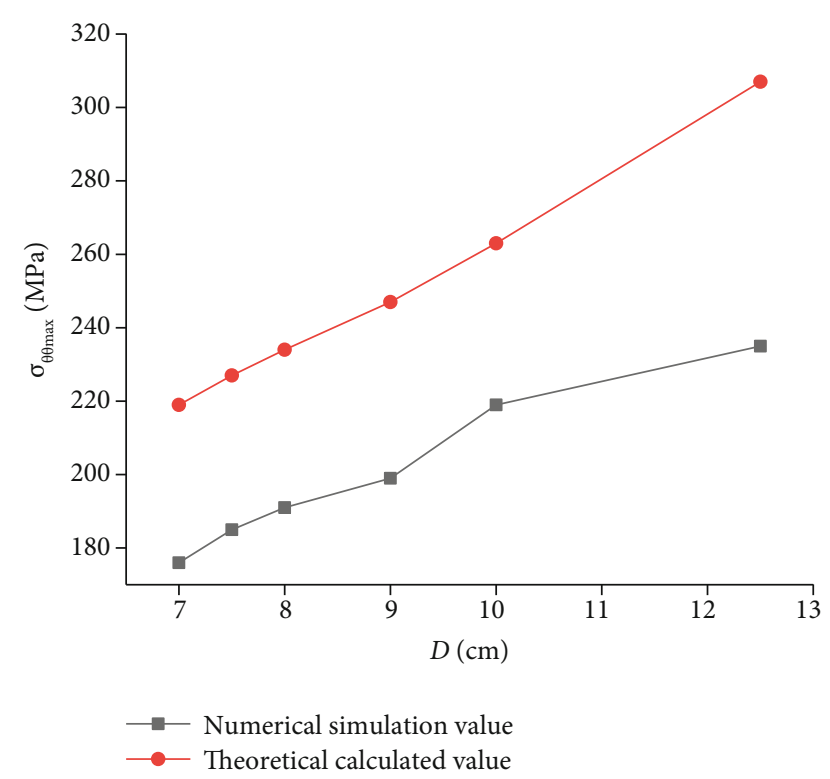

Figure 3: Comparison of maximum tensile stress between theoretical calculation and numerical simulation.

3.4. The Distance between the Empty Hole and the First Blast Hole. According to Scheme 2, after simulating different distances between the first blast hole and the empty hole, the damage range of the rock is shown in Table 6.

It can be seen that for the model of $20 \mathrm{~cm}$ hole spacing, after the blast, the width of the rock fragmentation zone is $70.21 \mathrm{~cm}$, and its cross-sectional area is $1651.7 \mathrm{~cm}^{2}$; when the hole spacing is $25 \mathrm{~cm}$, the width and the cross-sectional area of the rock fragmentation zone is $76.61 \mathrm{~cm}$ and $2182.9 \mathrm{~cm}^{2}$, respectively; for the $30 \mathrm{~cm}$ hole spacing, the rock fragmentation area is the largest, and the corresponding width and area is $83.1 \mathrm{~cm}$ and $2320.5 \mathrm{~cm}^{2}$.

\subsection{Spacing between the Empty Hole and the Second Blast} Hole. The simulation is carried out according to Scheme 3, during which after the two first blast holes detonate for $25 \mathrm{~ms}$, and the second blast hole detonates. The damage range of the rock is shown in Table 7 . The pore wall pressure time history curve at the hole wall is shown in Figure 4.

It can be seen that before detonation, as the hole distance increases, the peak compressive stress of the blast hole wall is $221 \mathrm{MPa}, 140 \mathrm{MPa}$, and $136 \mathrm{MPa}$, respectively, indicating that the smaller the distance between the second blast hole and the empty hole the greater the impact of the stress wave caused by the first blast hole. Besides, after the first blast hole is detonated, a large number of rock units around the second blast hole are destroyed, which is consistent with the actual situation. In the actual project, the explosives and detonators of the second hole may be "squeezed," which will affect the blast effect. When the spacing increases from $35 \mathrm{~cm}$ to $40 \mathrm{~cm}$, the peak stress of the wall of the second blast hole is reduced by $36.6 \%$, but when the spacing increases from $40 \mathrm{~cm}$ to $45 \mathrm{~cm}$, the peak pressure is only reduced by $2.8 \%$, indicating when the spacing is increased to a certain extent, the decreased amplitude of the pressure of the hole wall will be reduced. When the distance between the second blast hole and the empty hole is $40 \mathrm{~cm}$, the formed rock fragmentation zone is $88.7 \mathrm{~cm}$ in wide and $118.1 \mathrm{~cm}$ in high, and the cross-sectional area of the rock fragmentation zone is $6728 \mathrm{~cm}^{2}$; the cross-sectional area of the rock crushing area formed is the largest. Therefore, the distance between the second blast hole and the empty hole is $40 \mathrm{~cm}$.

3.6. Spacing between the Empty Hole and the Third Blast Hole. According to experimental Scheme 4, after the two first blast holes detonate, the second blast hole detonates for $25 \mathrm{~ms}$ and when the third blast hole detonates and lasts $25 \mathrm{~ms}$. The rock damage range is shown in Table 8. The pore wall pressure time history curve at the hole wall is shown in Figure 5.

After the first and second blast holes are detonated, with the increase of the hole spacing, the peak compressive stress of rock units around the third blast hole reaches $190 \mathrm{MPa}$, $70.5 \mathrm{MPa}$, and $49.3 \mathrm{MPa}$, respectively. When the horizontal and vertical distance between the third blast hole and the empty hole changes from $40 \mathrm{~cm}$ to $45 \mathrm{~cm}$, the peak compressive stress of the rock around the third blast hole drops by $62.8 \%$, and the rock is broken. At the same time, the crosssectional area of the rock fragmentation zone is increased by $16.8 \%$. When the horizontal and vertical distance changes from $45 \mathrm{~cm}$ to $50 \mathrm{~cm}$, the peak compressive stress of the rock drops by $30.1 \%$ after detonation, and the fissures around the holes are more fully developed; however, due to the larger blast hole spacing, the reflected tensile wave is weak, making the third segment of the blast hole unable to completely penetrate after the detonation, and the formation of the rock fragmentation area is not good. Therefore, the horizontal distance between the third blast hole and the empty hole is $45 \mathrm{~cm}$, and the vertical distance is $45 \mathrm{~cm}$.

\section{Field Verification Test}

4.1. Verification of Blast Hole Layout. The test site is in the middle section 285 of Dahongshan Copper Mine, level $370 \mathrm{~m}$. According to the existing data, the primary rock is marble, and the rock mechanic parameters are close to those used in the numerical simulation. In the test, the charge hole diameter is $5 \mathrm{~cm}$, the hollow hole diameter is $10 \mathrm{~cm}$, and the blast hole depth is $320 \mathrm{~cm}$. The section size of the blast test is $350 \mathrm{~cm}$ in wide and $330 \mathrm{~cm}$ in high. The cut area is located in the middle of the section, and the position is shown in Figure 1. The explosive used is the No. 1 rock emulsion explosive. According to the actual situation of the site, the charge coefficient is 0.8 , and the coupled charge form is adopted. Moreover, the hollow cutting scheme requires three sets of detonators to be delayed at equal intervals of $25 \mathrm{~ms}$. The sequence of initiation is as follows: the first blast holes I-1 and I-2 use two section detonators to detonate; the second blast holes II- 1 and II- 2 use four section detonators to detonate; the third blast holes III-1, III-2, III-3, and III-4 use six-section detonators to detonate. All the $25 \mathrm{~ms}$ equidistant delayed detonators are uniformly detonated by a magnetoelectric detonator. 
TABLE 6: Rock failure range under the distance between the first blast hole and the empty hole.

Simulation result

TABLE 7: Rock failure range at the distance between the second blast hole and the empty hole.

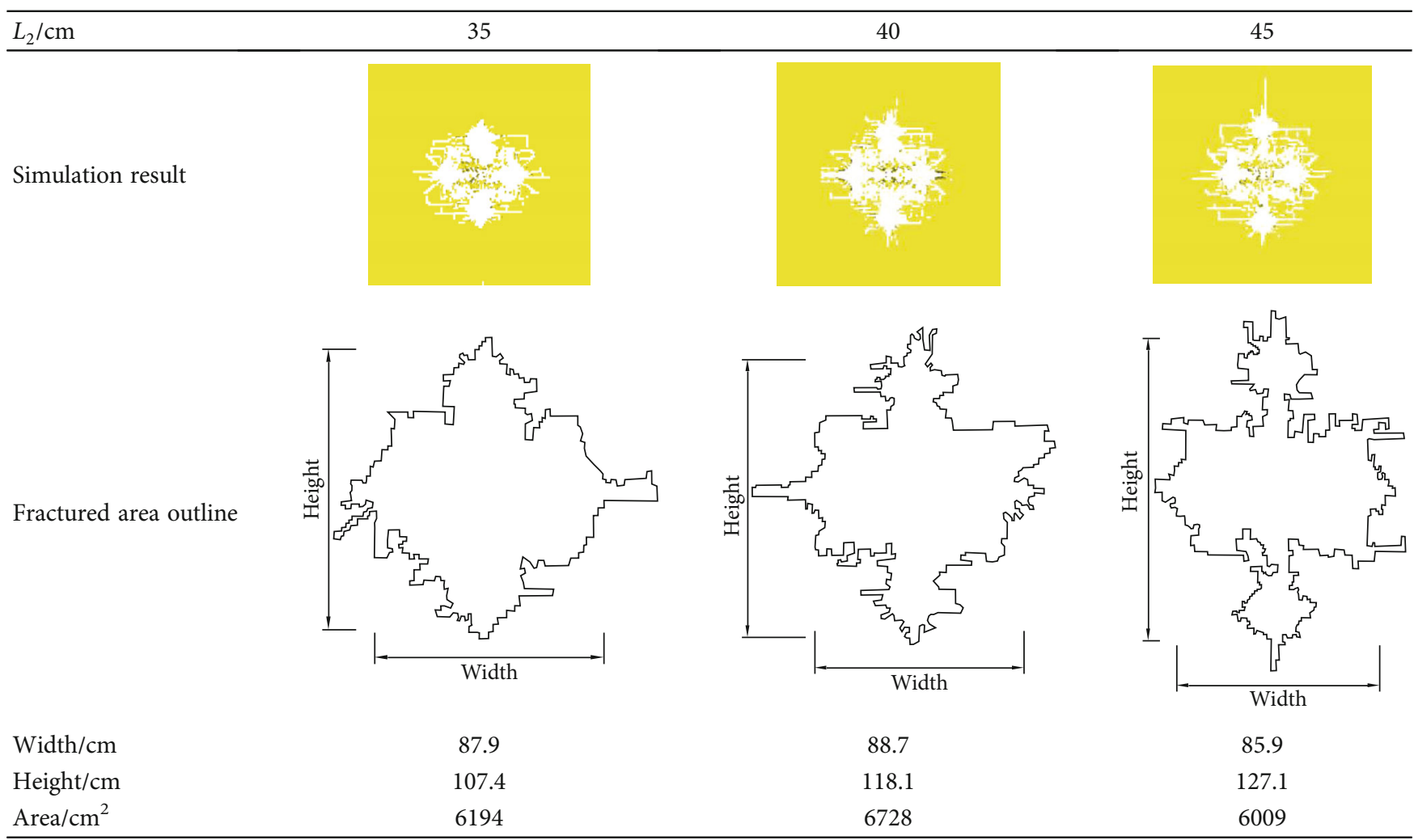

4.2. Effect and Analysis of Cavity Formation by Blast. After blast, the cavity is formed, as shown in Figure 6. The width and height of the cross-section of the cavity are measured and statistically calculated, as shown in Figure 7; In Figure 8 , the area of the cavity is calculated and compared with the simulation results, and the statistics data are shown in Table 9.
The cross-sectional area of the cavity in the field test of the large-diameter hole vertical cutting scheme is $5.3 \%$ smaller than that of the simulation results, the width of the cavity in the field test is $3.3 \%$ larger than that of the simulation results, and the height of the cavity in the field test is $3.4 \%$ smaller than that of the simulation results. It can be seen that the difference between the cavity data obtained 


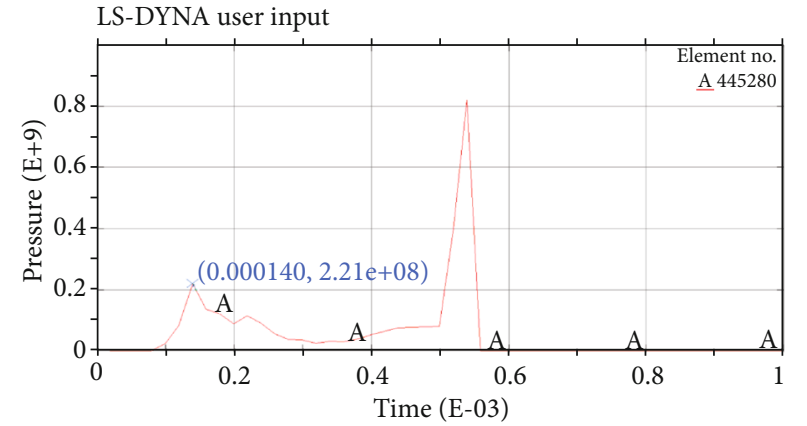

$\min =\mathrm{A}(0.001,0)$

$\max =\mathrm{A}(0.0054,8.23 \mathrm{e}+08)$

(a) $L_{2}=30 \mathrm{~cm}$

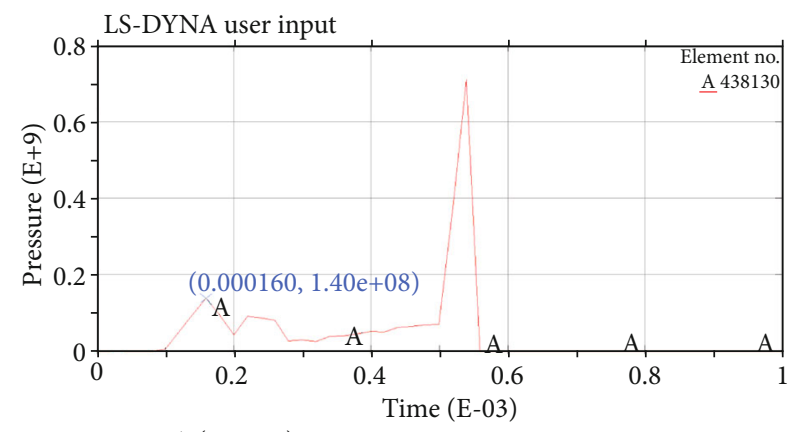

$\min =\mathrm{A}(0.001,0)$

$\max =\mathrm{A}(0.0054,7.12 \mathrm{e}+08)$

(b) $L_{2}=40 \mathrm{~cm}$

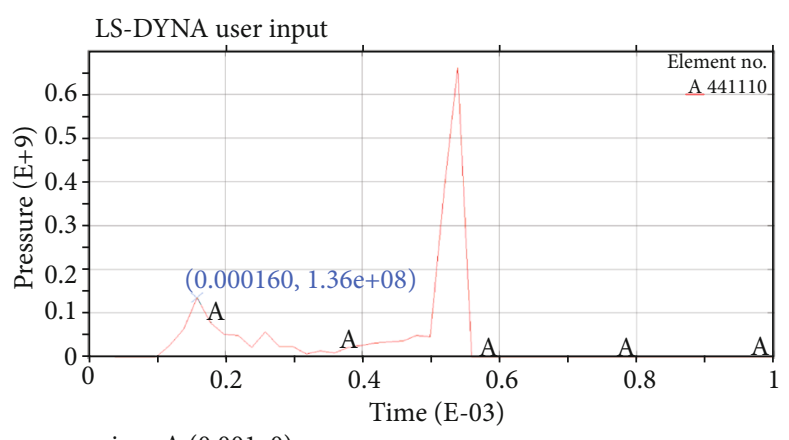

$\min =\mathrm{A}(0.001,0)$

$\max =\mathrm{A}(0.0054,6.63 \mathrm{e}+08)$

(c) $L_{2}=50 \mathrm{~cm}$

FIgUre 4: Pressure time history curve of hole wall.

TABLE 8: Rock failure range at the distance between the third blast hole and the empty hole.

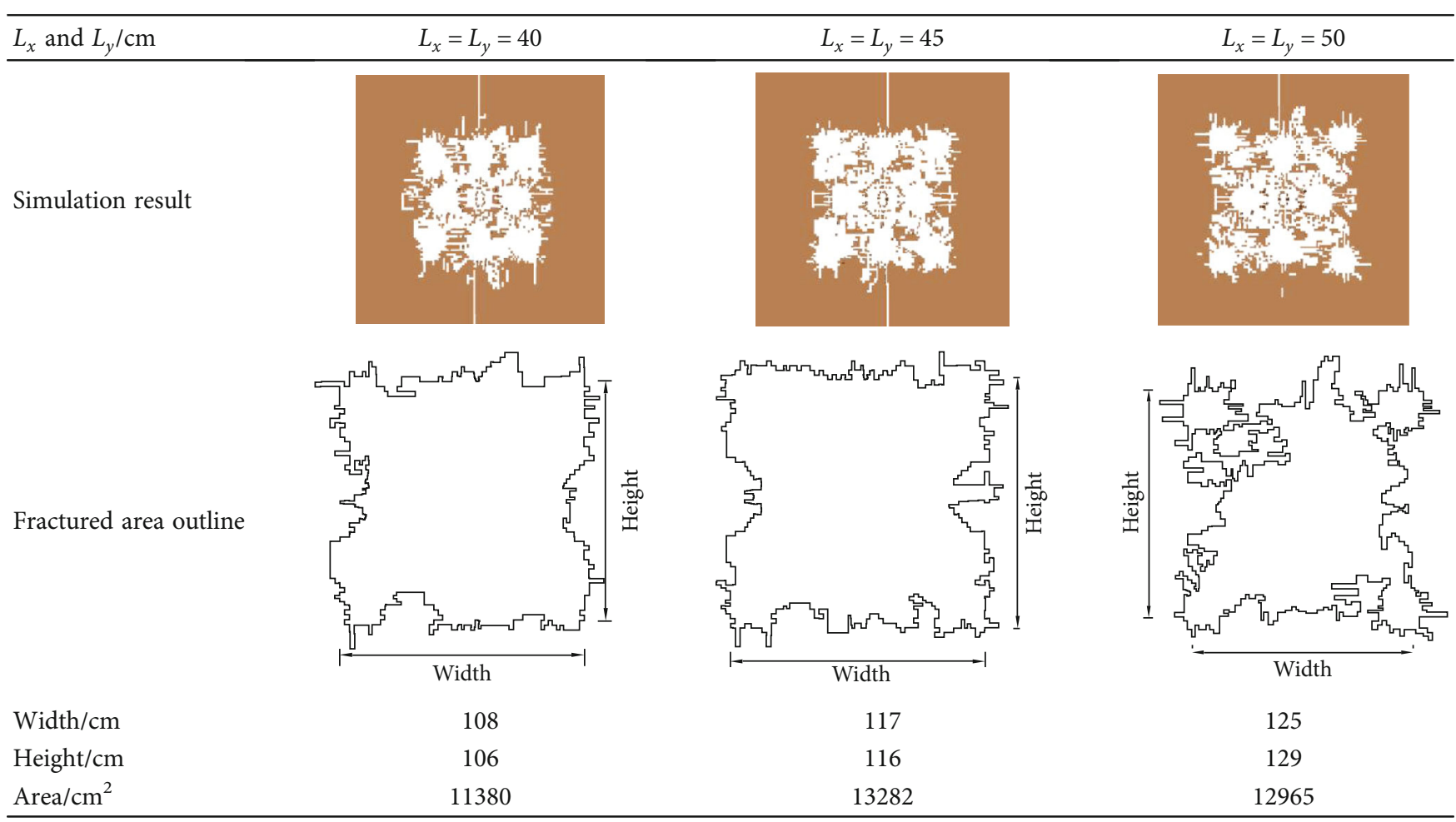




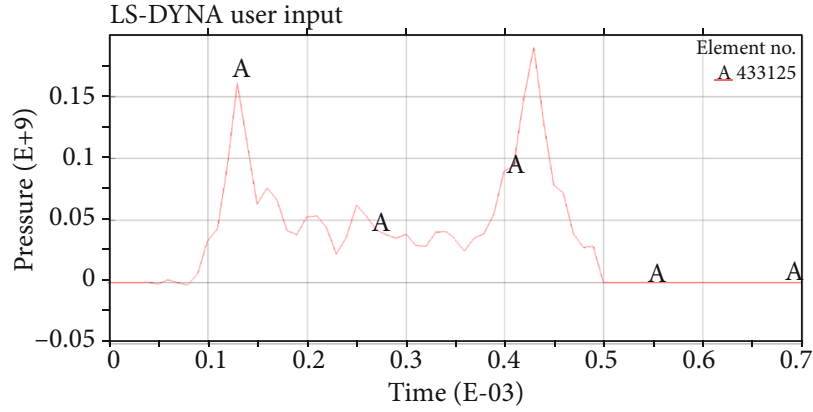

$\min =\mathrm{A}(8 \mathrm{e}-05,-1.79 \mathrm{e}+06)$ $\max =\mathrm{A}(0.00043,1.9 \mathrm{e}+08)$

(a) $L_{x}=L_{y}=40 \mathrm{~cm}$

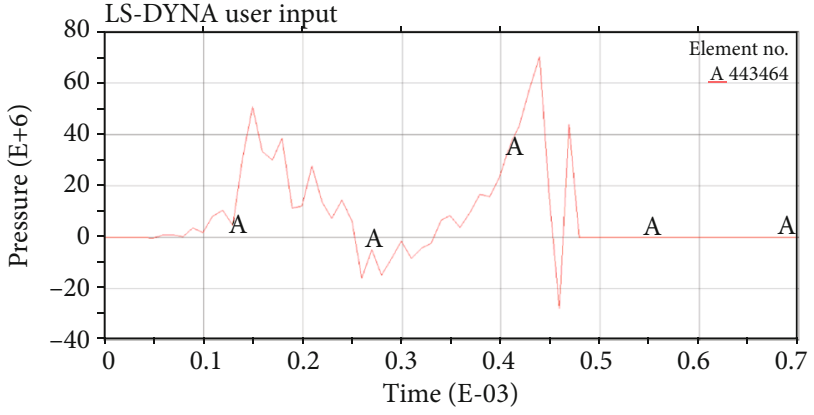

$\min =\mathrm{A}(0.00046,-2.76 \mathrm{e}+07)$

$\max =\mathrm{A}(0.00044,7.05 \mathrm{e}+07)$

(b) $L_{x}=L_{y}=45 \mathrm{~cm}$

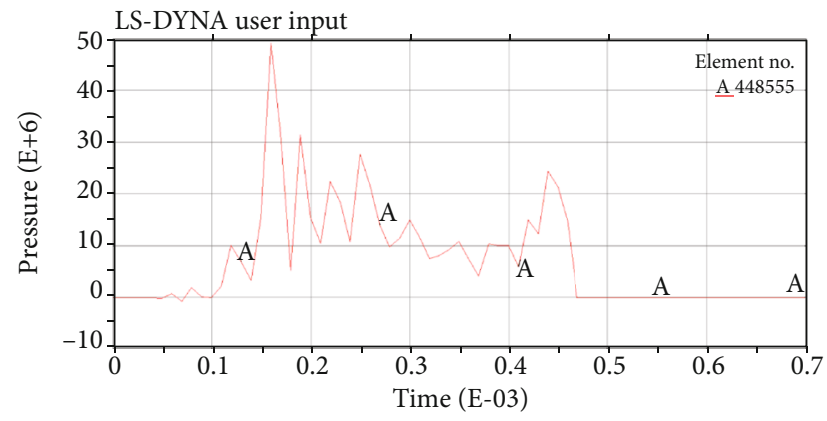

$\min =\mathrm{A}(7 \mathrm{e}-05,-6.76 \mathrm{e}+05)$

$\max =\mathrm{A}(0.00016,4.93 \mathrm{e}+07)$

(c) $L_{x}=L_{y}=50 \mathrm{~cm}$

Figure 5: Pressure time history curve of hole wall.

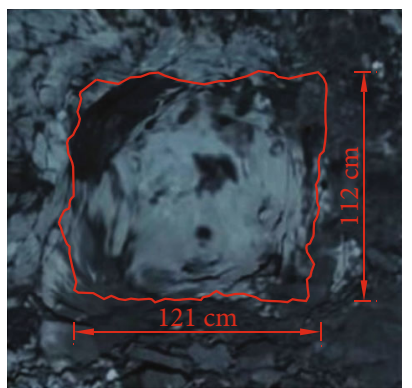

FIgURE 6: Blast effect diagram.

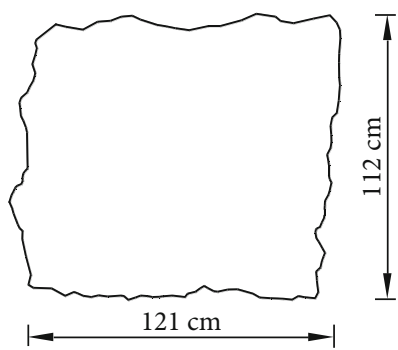

Figure 7: Contour of blast cavity.

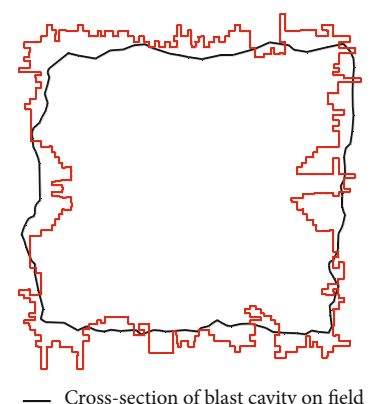

- Cross-section of blast cavity on field

Figure 8: Effect comparison.

TABLE 9: Blast effect statistic table.

\begin{tabular}{lccc}
\hline $\begin{array}{l}\text { Cutting } \\
\text { method }\end{array}$ & $\begin{array}{c}\text { Slot cavity } \\
\text { width } / \mathrm{cm}\end{array}$ & $\begin{array}{c}\text { Slot cavity } \\
\text { height } / \mathrm{cm}\end{array}$ & $\begin{array}{c}\text { Slot cavity cross- } \\
\text { sectional area } / \mathrm{cm}^{2}\end{array}$ \\
\hline $\begin{array}{l}\text { Test hollow } \\
\text { cut }\end{array}$ & 121 & 112 & 12500 \\
$\begin{array}{l}\text { Simulated } \\
\text { hollow cut }\end{array}$ & 117 & 116 & 13200 \\
\hline
\end{tabular}


from the field test and the numerical simulation results is within $6 \%$.

\section{Discussion}

In this paper, through combining theoretical calculation and numerical simulation, taking the rock fracture area as the evaluation basis, the diameter of the empty hole and the position of the cutting hole are gradually determined, and the reliability of the hole distribution parameters is verified by the field test. However, in this method, the rock is assumed to be completely homogeneous, without considering the influence of joints, cracks, and groundwater in the rock on the blasting effect. At the same time, only the marble lithology is selected to study, and the actual working condition is a composite rock mass dominated by marble; so, there must be some errors in the numerical calculation results. In addition, this study only analyzes the contour section after blasting by two-dimensional model and cannot obtain the influence of the hole depth on the cyclic footage in the cutting blasting. After the field test, only the section size of the cutting cavity is measured, and the cutting blasting effect is verified.

\section{Conclusion}

In this paper, through theoretical calculation and ANSYS/ LS-DYNA numerical simulation method, the influence of cutting hole arrangement on the size of cavity contour surface after blasting is studied, and the following conclusions are obtained:

(1) The maximum tensile stress will be generated at the wall of the empty hole closest to the center of the charge hole, and the tensile stress of the rock unit at the empty hole wall increases with the increase of the diameter of the empty hole diameter. According to the drilling cost and the actual mine equipment, the empty hole diameter is finally selected as $10 \mathrm{~cm}$

(2) Taking the empty hole with a diameter of $10 \mathrm{~cm}$ as the center, two holes $30 \mathrm{~cm}$ away from the empty hole are arranged horizontally symmetrically as the first blast, two holes $40 \mathrm{~cm}$ away from the empty hole are arranged vertically symmetrically as the second blast, and four holes are arranged squarely as the third blast. The contour area of the cavity after blasting is the largest

(3) The field test shows the errors of the section area, width, and height and numerical simulation results of the cavity are within $6 \%$, indicating that the combination of theoretical calculation and numerical simulation can be used to predict the contour section area after blast of cutting holes in roadway excavation. This numerical simulation method can be further expanded from two-dimensional to threedimensional to study the cavity formation effect under different cutting modes and selectively carry out field test verification, so as to find a numerical method to predict the cavity formation effect of underground roadway cutting blasting

\section{Data Availability}

The data used to support the findings of this study are included in the article.

\section{Conflicts of Interest}

The authors declare that they have no conflicts of interest.

\section{Authors' Contributions}

Conceptualization, methodology, validation, data curation, visualization, writing-original draft preparation were contributed by J.W. and Z.T. Experimental guidance and data analysis were performed by Q.L. and Z.W. Theoretical analysis was contributed by X.L. and H.W. Formal analysis writing-review and editing was contributed by all authors. All authors have read and agreed to the published version of the manuscript. Qiang Li is the co-first author.

\section{Acknowledgments}

This study was financially supported by the National Natural Science Foundation of China (No. 51934003), and its support is gratefully appreciated.

\section{References}

[1] P. Q. Lu, G. S. Li, Z. W. Huang, S. C. Tian, Z. H. Shen, and X. J. $\mathrm{Li}$, "Numerical simulation for stress disturbance features of coal beds during pulsating hydro-fracturing," Journal of Shock and Vibration, vol. 34, no. 21, pp. 210-216, 2015.

[2] J. Yang, H. Lian, and L. Li, "Fracturing in coals with different fluids: an experimental comparison between water, liquid $\mathrm{CO}_{2}$, and supercritical $\mathrm{CO}_{2}$," Scientific Reports, vol. 10, no. 1, 2020.

[3] B. B. Zhong, H. Li, and Y. B. Zhang, "Numerical simulation of rock dynamic crack propagation under explosion load," Explosion and Shock Wave, vol. 36, no. 6, pp. 825-831, 2016.

[4] Z. R. Zhang, J. J. Zuo, and Y. X. Guo, "Study on the influence mechanism of empty holes and their defects on crack propagation under explosive load," Journal of Vibration and Shock, vol. 38, no. 18, pp. 115-121, 2019.

[5] B. Mohanty, "Explosion generated fractures in rock and rocklike materials," Journal of China university of Mining \& Technology, vol. 35, no. 4-5, pp. 889-898, 1990.

[6] S. H. Cho, Y. Nakamura, B. Mohanty, H. S. Yang, and K. Kaneko, "Numerical study of fracture plane control in laboratory-scale blasting," Engineering Fracture Mechanics, vol. 75, no. 13, pp. 3966-3984, 2008.

[7] Z. Y. Lai, "Analysis on blasting effect of parallel cut with empty hole in tunnel construction," IOP Conference Series: Earth and Environmental Science, vol. 719, no. 3, p. 032002, 2021.

[8] Z. Y. Wu, D. Luo, F. Chen, and W. Huang, "Numerical simulation of empty-hole effect during parallel-hole cutting under different in situ stress conditions," Advances in Civil Engineering, vol. 2021, Article ID 8881491, 11 pages, 2021. 
[9] G. B. Tian, J. Dai, Y. Wu, X. Xiong, and Z. Chen, "Influence of charge hole spacing on the crack propagation behavior under the effect of empty-hole directional blasting," Advances in Civil Engineering, vol. 2020, Article ID 8860816, 10 pages, 2020.

[10] H. C. Li, X. T. Zhang, D. Li et al., "Numerical simulation of the effect of empty hole between adjacent blast holes in the perforation process of blasting," Journal of Intelligent \& Fuzzy Systems, vol. 37, no. 3, pp. 3137-3148, 2019.

[11] X. B. Zheng, S. J. Qu, L. H. Fan, and Y. Wang, "Numerical simulation study on the process of single spiral hollow straight-eye cutting into cavity," Rock and Soil Mechanics, vol. 153, no. 9, pp. 2589-2594, 2008.

[12] Q. Zong, L. P. Yan, and H. B. Wang, "Numerical simulation analysis on explosion stress field of different charge construction," Advanced Materials Research, vol. 1270, no. 13, pp. 2612-2616, 2011.

[13] B. Y. Zhu, Y. He, W. Y. Jiao, and Y. Kang, "Numerical simulation of hollow hole effect in straight hole cutting blast," Mining Research and Development, vol. 40, no. 2, pp. 58-61, 2020.

[14] Z. W. Yue, Y. Guo, X. Wang, H. B. Yang, and T. X. Han, "Study on the influence of hole shape on directional fracture blast of rock," Rock and Soil Mechanics, vol. 37, no. 2, pp. 376-382, 2016.

[15] Q. Zhang, Y. Q. Yang, Y. F. Yuan, X. L. Wang, and D. C. Lin, "Analysis of influencing factors of straight-hole cutting blast effect," Rock and Soil Mechanics, vol. 2001, no. 2, pp. 144147, 2001.

[16] Q. Y. Li, M. Xu, Z. P. Fan, and W. H. Wang, "Rock breaking process simulation and hole effect analysis of straight hole cutting," Blast, vol. 28, no. 4, pp. 23-26, 2011.

[17] H. B. Wang, Q. Zong, and Y. C. Zhao, "Numerical simulation analysis and application of vertical shaft large diameter hollow hole straight hole blast stress field," Chinese Journal of Rock Mechanics and Engineering, vol. 34, Supplement 1, pp. 32233229, 2015.

[18] Z. Liu, X. Ren, X. Lin, H. Lian, L. Yang, and J. Yang, "Effects of confining stresses, pre-crack inclination angles and injection rates: observations from large-scale true triaxial and hydraulic fracturing tests in laboratory," Rock Mechanics and Rock Engineering, vol. 53, no. 4, pp. 1991-2000, 2020.

[19] Z. Liu, J. Yang, L. Yang, X. Ren, X. Peng, and H. Lian, "Experimental study on the influencing factors of hydraulic fracture initiation from prefabricated crack tips," Engineering Fracture Mechanics, vol. 250, p. 107790, 2021.

[20] S. Y. Xiao, Y. J. Jiang, Z. X. Liu, and L. J. Su, "Research on rock breaking characteristics and energy distribution of hard rock blast under high ground stress," Journal of Vibration and Shock, vol. 37, no. 15, pp. 143-149, 2018.

[21] Z. R. Li, X. L. Feng, H. W. Liu, M. Wu, X. D. Cui, and M. W. Liu, "Underground ore parallel center large hole blast trenching technology," Metal Mine, vol. 505, no. 7, pp. 78-81, 2018.

[22] J. Ma, X. Li, J. Wang et al., "Numerical simulation on selection of optimal delay time for precise delay blasting," Shock and Vibration, vol. 2021, Article ID 4593221, 9 pages, 2021.

[23] P. Li, Y. J. Wang, and B. Ke, "Theoretical calculation of hole spacing of progressive spiral cutting," Blast, vol. 28, no. 4 , pp. 20-22, 2011.

[24] B. L. Huang, "Application of large diameter hollow straight hole cutting technology in tunnel rescue," Blast, vol. 35, no. 4, pp. 74-77, 2018.
[25] Y. J. Tian, G. L. Guo, J. G. Kang, and J. H. Gang, "Simulation of stone cutting process based on adaptive coupling method," Journal of System Simulation, vol. 30, no. 2, pp. 497-505, 2018.

[26] Q. D. Gao, W. B. Lu, Z. D. Leng, Z. W. Yang, P. Yan, and M. Chen, "Optimization of initiation position of cut hole during tunnel excavation," Journal of Vibration and Shock, vol. 37, no. 9, pp. 8-16, 2018.

[27] D. Y. Fan, X. S. Liu, Y. L. Tan, S. L. Song, J. G. Ning, and Q. Ma, "Numerical simulation research on response characteristics of surrounding rock for deep super-large section chamber under dynamic and static combined loading condition," Journal of Central South University, vol. 27, no. 12, pp. 3544-3566, 2020.

[28] S. Cui, S. Y. Liu, and J. Huang, "The experimental study of directional fracturing and rock breaking under the action of open hole," Journal of Central South University (Natural Science Edition), vol. 52, no. 5, pp. 1570-1580, 2021.

[29] Y. Zhou, D. Zhao, B. Li, H. Y. Wang, Q. Q. Tang, and Z. Z. Zhang, "Fatigue damage mechanism and deformation behaviour of granite under ultrahigh-frequency cyclic loading conditions," Rock Mechanics and Rock Engineering, vol. 54, no. 9, pp. 4723-4739, 2021.

[30] Y. G. Zhang and L. Yang, "A novel dynamic predictive method of water inrush from coal floor based on gated recurrent unit model," Natural Hazards, vol. 105, no. 2, pp. 2027-2043, 2020.

[31] R. Kumar, P. K. Mandal, A. Narayan, and A. J. Das, "Evaluation of load transfer mechanism under axial loads in a novel coupler of dual height rock bolts," International Journal of Mining Science and Technology, vol. 31, no. 2, pp. 225-232, 2021.

[32] Y. G. Zhang, Y. L. Xie, Y. Zhang, J. B. Qiu, and S. X. Wu, "The adoption of deep neural network (DNN) to the prediction of soil liquefaction based on shear wave velocity," Bulletin of Engineering Geology and the Environment, vol. 80, no. 6, pp. 5053-5060.

[33] X. S. Liu, S. L. Song, Y. L. Tan et al., "Similar simulation study on the deformation and failure of surrounding rock of a large section chamber group under dynamic loading," International Journal of Mining Science and Technology, vol. 31, no. 3, pp. 495-505, 2021.

[34] X. S. Liu, D. Fan, Y. Tan et al., "New detecting method on the connecting fractured zone above the coal face and a case study," Rock Mechanics and Rock Engineering, vol. 54, no. 8, pp. 4379-4391, 2021.

[35] A. I. Lawal, S. Kwon, O. S. Hammed, and M. A. Idris, "Blastinduced ground vibration prediction in granite quarries: an application of gene expression programming, ANFIS, and sine cosine algorithm optimized ANN," International Journal of Mining Science and Technology, vol. 31, no. 2, pp. 265-277, 2021.

[36] X. S. Liu, D. Fan, Y. Tan et al., "Failure evolution and instability mechanism of surrounding rock for close-distance parallel chambers with super-large section in deep coal mines," International Journal of Geomechanics, vol. 21, no. 5, p. 04021049 , 2021.

[37] Z. D. Leng, Y. Fan, Q. D. Gao, and Y. G. Hu, "Evaluation and optimization of blasting approaches to reducing oversize boulders and toes in open-pit mine," International Journal of Mining Science and Technology, vol. 30, no. 3, pp. 373-380, 2020.

[38] I. Vennes, H. Mitri, D. R. Chinnasane, and M. K. Yao, "Largescale destress blasting for seismicity control in hard rock mines: a case study," International Journal of Mining Science and Technology, vol. 30, no. 2, pp. 141-149, 2020. 